\title{
Characterization of the interface region during the agglomeration of silicon nanocrystals in silicon dioxide
}

\author{
X. D. Pi and P. G. Coleman ${ }^{\text {a) }}$ \\ Department of Physics, University of Bath, Bath BA2 7AY, United Kingdom \\ R. Harding and G. Davies \\ Department of Physics, King's College London, Strand, London WC2R 2LS, United Kingdom
}

R. M. Gwilliam

School of Electronics, Computing, and Mathematics, University of Surrey, Guildford, Surrey GU2 7XH, United Kingdom

(Received 10 November 2003; accepted 19 March 2004)

\begin{abstract}
$\mathrm{Si}$ nanocrystals embedded in thermally grown $\mathrm{SiO}_{2}$ have been annealed at temperatures between 400 and $900{ }^{\circ} \mathrm{C}$ in a variety of atmospheres. Positron annihilation spectroscopy has been employed to study changes in the interface regions between nanocrystalline $\mathrm{Si}(\mathrm{nc}-\mathrm{Si})$ and $\mathrm{SiO}_{2}$ with the support of photoluminescence measurements. We find that nitrogen and oxygen are trapped in the voids around $\mathrm{nc}-\mathrm{Si}$ at low annealing temperatures. High-temperature annealing during the formation of nc-Si causes hydrogen originally residing in the $\mathrm{SiO}_{2} /$ substrate region to enter the $\mathrm{SiO}_{2}$ structure. Hydrogen diffuse back to the $\mathrm{SiO}_{2} /$ substrate region on annealing in vacuum at $400{ }^{\circ} \mathrm{C}$ because no other impurities block its diffusion channels. At annealing temperatures above $700{ }^{\circ} \mathrm{C}$, both nitrogen and oxygen react with nc-Si, resulting in a volume increase. This introduces stress in the $\mathrm{SiO}_{2}$ matrix, which is relaxed by the shrinkage of its intrinsic open volume. The present data suggest that nitrogen suppresses $\mathrm{Si}$ diffusion in $\mathrm{SiO}_{2}$, so that the agglomeration of nc-Si is slower during annealing in nitrogen than in oxygen or vacuum. (C) 2004 American Institute of Physics.
\end{abstract}

[DOI: $10.1063 / 1.1738539$ ]

\section{INTRODUCTION}

The study of nanometer-sized semiconductors is an active field of research because of applications in advanced electronic and optoelectronic devices and photovoltaic cells. The major advantage of using nanometer-sized semiconductors is that their optical and electrical properties can be tailored simply by size alteration without changing the chemical composition of the materials. $\mathrm{Si}$ is dominant in microelectronics but, as an indirect-bandgap semiconductor, it is not an efficient light emitter. This causes a serious problem of optoelectronic integration that, however, may be solved when the dimension of $\mathrm{Si}$ is reduced to the nanometer-sized regime. Recently, optical gain has been achieved in nanocrystalline $\mathrm{Si}$ (nc-Si), ${ }^{1,2}$ opening a route to the fabrication of a Si laser on a microelectronic chip. While it is generally accepted that the bandgap of $\mathrm{Si}$ widens as a result of quantum confinement, which causes the blueshift of photoluminescence (PL) for $\mathrm{Si}$ crystallite size below $5 \mathrm{~nm},{ }^{3}$ it is also believed that the interface between nc-Si and $\mathrm{SiO}_{2}$ plays a role in the radiative emission of $\mathrm{nc}-\mathrm{Si}$, especially when its size is smaller than $3 \mathrm{~nm} .{ }^{4}$ Therefore, it is desirable to pay close attention to the interfaces associated with nc-Si.

Positron annihilation spectroscopy (PAS) with a slow positron beam has demonstrated its power in the investigation of the interface between $\mathrm{SiO}_{2}$ and $\mathrm{Si}$ substrates. ${ }^{5,6}$ It is known that positrons can be easily trapped at open-volume

\footnotetext{
${ }^{a)}$ Electronic mail: p.g.coleman@bath.ac.uk
}

defects as a result of the missing positive-ion cores at these defects. This trapping usually gives rise to a narrowing of the annihilation gamma energy spectrum (centered at $511 \mathrm{keV}$ ) compared with that for positron annihilation in defect-free sites. This narrowing is characterized by an increase in the parameter $S$, defined as the central fraction of the annihilation spectrum. ${ }^{7}$ However, $S$ is also sensitive to impurities such as hydrogen, ${ }^{8-11}$ oxygen, ${ }^{12,13}$ fluorine, ${ }^{14,15}$ and nitrogen ${ }^{6}$ when they decorate the open-volume defects in semiconductors, a decrease in measured $S$ values is generally observed. In this work, PAS and PL are employed to study the interface between nc-Si and $\mathrm{SiO}_{2}$. Changes of the interface region during the agglomeration of $\mathrm{nc}-\mathrm{Si}$ in $\mathrm{SiO}_{2}$ in different atmospheres are elucidated.

\section{EXPERIMENTAL PROCEDURE}

$\mathrm{Si}$ ions of $150 \mathrm{keV}$ were implanted to a dose of $1.6 \times 10^{17} \mathrm{~cm}^{-2}$ into a 500 -nm-thick layer of $\mathrm{SiO}_{2}$ thermally grown in dry oxygen on (100) Czochralski Si ( $p$-type, 10 $\Omega \mathrm{cm}$ ). The sample was then annealed at $1100{ }^{\circ} \mathrm{C}$ for $1 \mathrm{~h} \mathrm{in}$ nitrogen to produce nc-Si dispersed in $\mathrm{SiO}_{2}$. The nanocrystals are $\sim 3 \mathrm{~nm}$ in diameter on average, with a concentration of $2 \times 10^{19} \mathrm{~cm}^{-3}$ in a region centered at a depth of $\sim 200 \mathrm{~nm}$ from the $\mathrm{SiO}_{2}$ surface. The PL spectrum of the as-formed nanocrystals has a peak at $800 \mathrm{~nm}$, demonstrating the similarity of the present nanocrystals to those in Ref. 1. Further annealing of this sample was carried out between 400 and $900{ }^{\circ} \mathrm{C}$ for $30 \mathrm{~min}$ in nitrogen, oxygen, and vacuum. In the former two, a furnace with flowing gas was used, and in the 
last, electron bombardment was employed at a pressure of $\sim 10^{-4} \mathrm{~Pa}$. Beam-based PAS ${ }^{16}$ and PL were used to measure these annealed samples. Depth-sensitive PAS was performed by implanting positrons with controllable energies in the range $0.5-30 \mathrm{keV}$, corresponding to mean depths from $6 \mathrm{~nm}$ to $4 \mu \mathrm{m}$. PL measurements were made at room temperature using a photomultiplier detector; excitation was via the 514 $\mathrm{nm}$ line of an argon laser at a power $\sim 100 \mathrm{~mW}$ and a beam diameter $\sim 0.5 \mathrm{~mm}$. The luminescence was measured with a Spex spectrometer with a slit width of $600 \mu \mathrm{m}$ in the range $580-910 \mathrm{~nm}$. Experimental conditions such as laser power and orientation with respect to the laser beam and spectrometer were kept constant as far as possible. A correction was necessary to account for the wavelength-dependent response of the system. This was done by measuring spectra of a constant-power tungsten lamp and comparing the measured spectra with its calculated spectra. ${ }^{17}$ The apparent temperature of the tungsten lamp was measured using a pyrometer with a red filter.

\section{RESULTS}

\section{A. Annealing in nitrogen}

Figures 1(a) and 1(b) show the change of the PL spectra from these nanocrystals after annealing at 700 and $900{ }^{\circ} \mathrm{C}$ in nitrogen, respectively. The PL spectrum of the sample after $400{ }^{\circ} \mathrm{C}$ annealing is essentially the same as that of the asformed sample, and thus is not shown. After $700{ }^{\circ} \mathrm{C}$ annealing, the position of the PL peak remains the same, but the short-wavelength side becomes wider. A small redshift is observed after $900{ }^{\circ} \mathrm{C}$ annealing. It is assumed that the luminescence from the as-formed sample derives from both quantum confinement and interface state radiation because the sizes of nanocrystals are not uniform and their average size $(3 \mathrm{~nm})$ is on the boundary between the two mechanisms. ${ }^{4}$

PAS results for the samples annealed in nitrogen are shown in Fig. 2. The $S$ curves for the virgin $\mathrm{SiO}_{2} / \mathrm{Si}$ and high-temperature annealed $\mathrm{SiO}_{2} / \mathrm{Si}\left(1100^{\circ} \mathrm{C}, \mathrm{N}_{2}\right)$ are also included for comparison. All the $S$ values presented here have been normalized with respect to that for the defect-free $\mathrm{Si}$ bulk. The interface between $\mathrm{SiO}_{2}$ and $\mathrm{Si}$ substrate is indicated by a dip at $\sim 7 \mathrm{keV}$ in the $S$ curve for the virgin $\mathrm{SiO}_{2} / \mathrm{Si}$, which corresponds to a mean depth of $\sim 400 \mathrm{~nm}$. The dip can be explained by the residual hydrogen at the interface region. ${ }^{18}$ Here, the apparent position of the interface is slightly shallower than the expected $500 \mathrm{~nm}$ because of the smearing caused by the broad annihilation profile and positron diffusion effects. ${ }^{5}$ It is seen that $S$ values (from now on $S$ values refer to those for the $\mathrm{SiO}_{2}$ layer if not stated) for the as-formed sample are significantly smaller than those for the annealed virgin sample $\left(1100^{\circ} \mathrm{C}, \mathrm{N}_{2}\right)$. After the sample is annealed at $400{ }^{\circ} \mathrm{C}, S$ values decrease, and then remain unchanged after annealing at 550 (not shown) and $700^{\circ} \mathrm{C}$. From $800^{\circ} \mathrm{C}$ (not shown), $S$ values begin to recover, becoming even larger than those for the as-formed sample after $900^{\circ} \mathrm{C}$ annealing.

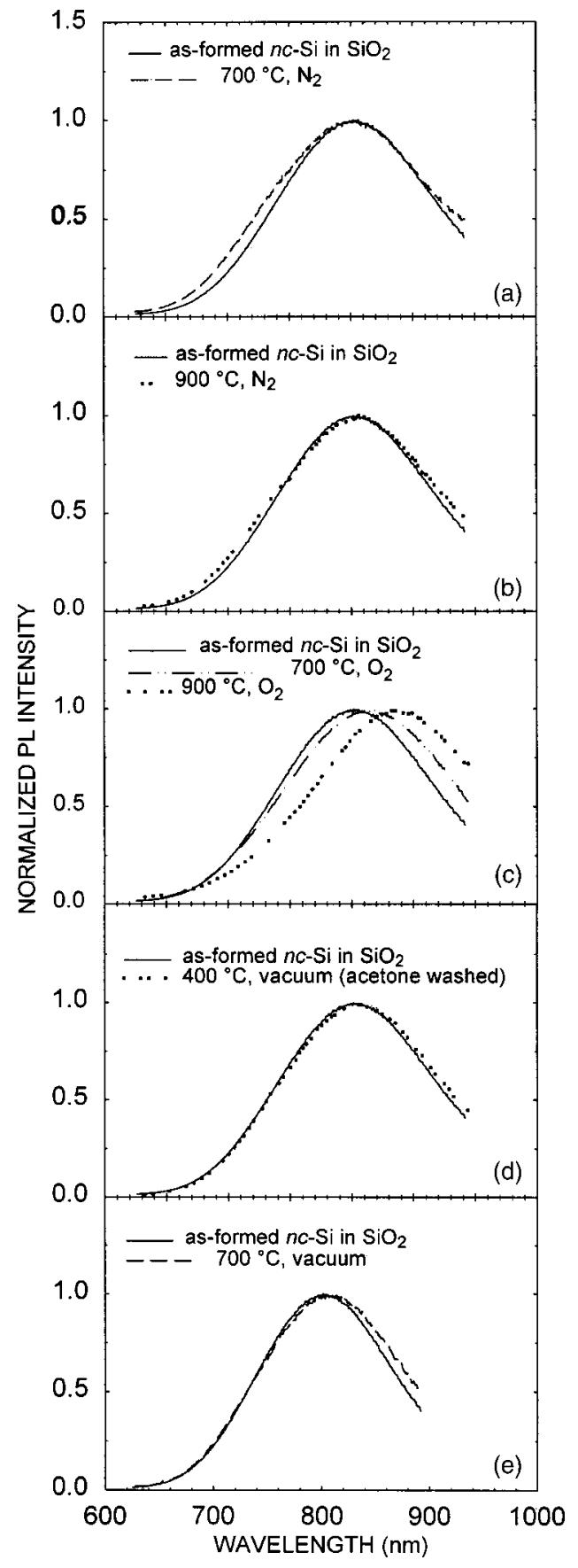

FIG. 1. PL spectra of the as-formed sample and those annealed at (a) 700 and (b) $900{ }^{\circ} \mathrm{C}$ in nitrogen, (c) 700 and $900{ }^{\circ} \mathrm{C}$ in oxygen, and (d) 400 and (e) $700{ }^{\circ} \mathrm{C}$ in vacuum. The sample annealed at $400^{\circ} \mathrm{C}$ in vacuum was washed with acetone shortly before annealing.

\section{B. Annealing in oxygen}

Figure 3 shows the PAS results for the samples annealed in oxygen. As in nitrogen, $S$ values decrease after $400{ }^{\circ} \mathrm{C}$ annealing. With temperature, they continue to fall until a minimum is met at $700^{\circ} \mathrm{C}$. As in nitrogen, $S$ values then rise from $800^{\circ} \mathrm{C}$ and, after annealing at $900^{\circ} \mathrm{C}$ they become nearly the same as those for the as-formed sample.

After annealing in oxygen at $400^{\circ} \mathrm{C}$, the PL spectrum shows no change, as in nitrogen. However, the clear PL redshifts for the samples annealed at 700 and $900{ }^{\circ} \mathrm{C}$ in oxygen are illustrated in Fig. 1(c). 


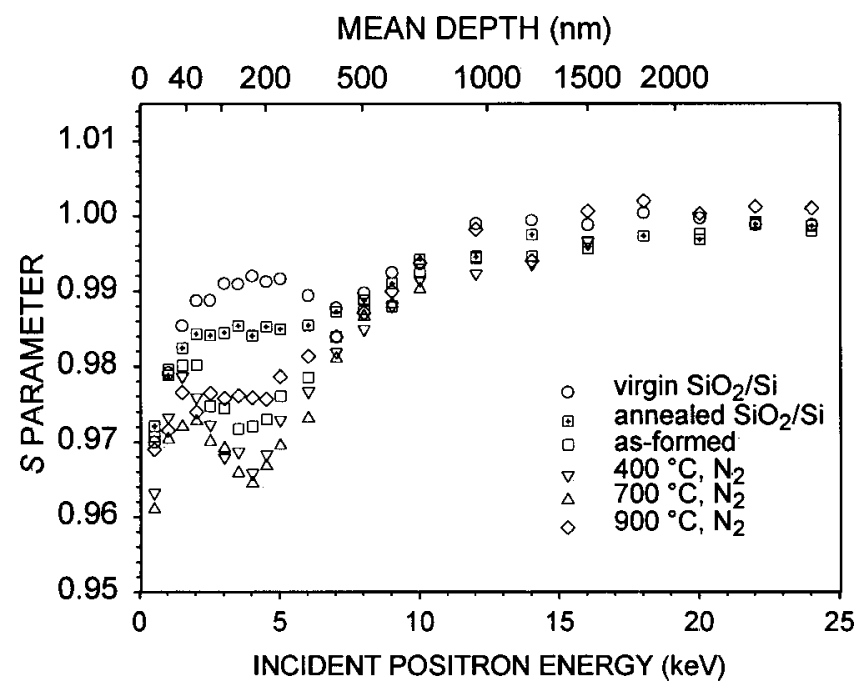

FIG. 2. PAS results of the as-formed sample and those annealed in nitrogen. The virgin and high-temperature annealed $\mathrm{SiO}_{2} / \mathrm{Si}$ samples are included for comparison.

\section{Annealing in vacuum}

The PAS results for the samples annealed in vacuum are shown in Fig. 4. After $400^{\circ} \mathrm{C}$ annealing, $S$ values do not change in the $\mathrm{SiO}_{2}$ layer. The $S$ values for the region around $\mathrm{SiO}_{2} /$ substrate (500 $\mathrm{nm}$ mean depth) are, however, reduced significantly. When the temperature is increased to $500^{\circ} \mathrm{C}$, these values become slightly smaller than those for the asformed sample, and the change in $S$ for the $\mathrm{SiO}_{2}$ layer is still negligible. The data for the annealing at $700{ }^{\circ} \mathrm{C}$ are similar to those for the as-formed sample, and are not shown. The change in the $\mathrm{SiO}_{2}$ /substrate region during the present annealing is consistent with a model of the decoration of interface defects by hydrogen. ${ }^{9}$ No change in the $\mathrm{SiO}_{2}$ layer indicates that the decoration of the defects at the nc-Si/SiO interface is negligible. This implies that hydrogen mainly enters the normal $\mathrm{SiO}_{2}$ structure during the high-temperature

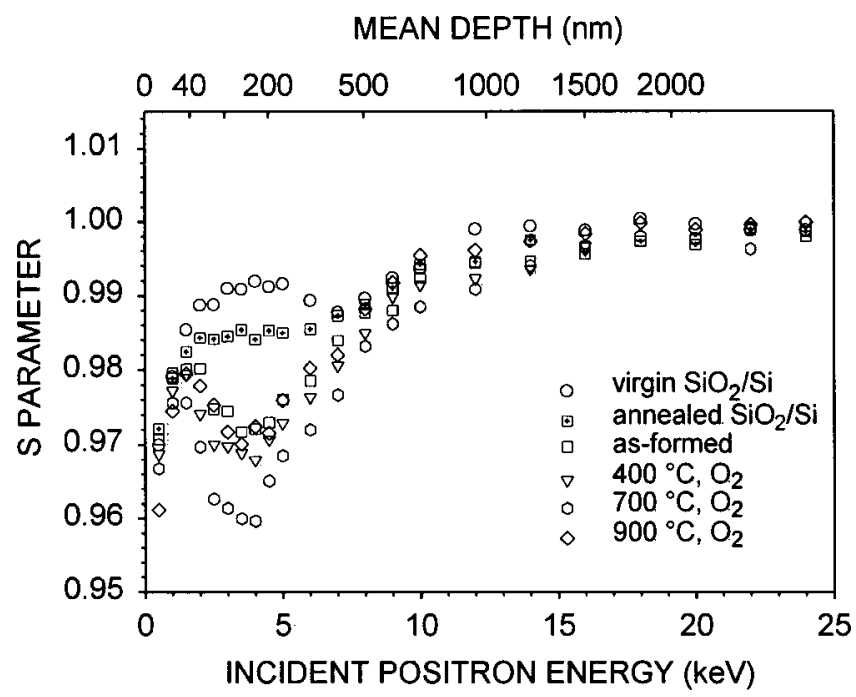

FIG. 3. PAS results of the as-formed sample and those annealed in oxygen. The virgin and high-temperature annealed $\mathrm{SiO}_{2} / \mathrm{Si}$ samples are included for comparison.

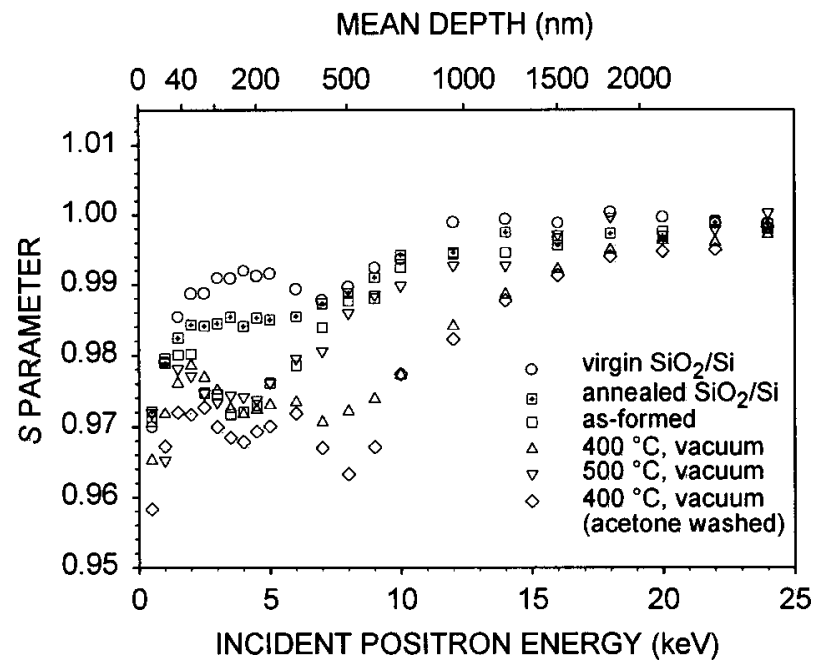

FIG. 4. PAS results of the as-formed sample and those annealed in vacuum. The virgin and high-temperature annealed $\mathrm{SiO}_{2} / \mathrm{Si}$ samples are included for comparison.

formation process of nc-Si (see Sec. IV). In addition, we find that $S$ values for both $\mathrm{SiO}_{2}$ layer and $\mathrm{SiO}_{2} /$ substrate decrease if the sample is washed with acetone shortly before $400{ }^{\circ} \mathrm{C}$ annealing in vacuum.

No change in PL after $400^{\circ} \mathrm{C}$ annealing in vacuum is observed. However, the additional acetone washing induces a small redshift of the PL peak, illustrated in Fig. 1(d). Also shown is the clear redshift after $700^{\circ} \mathrm{C}$ annealing in vacuum [Fig. 1(e)].

\section{DISCUSSION}

According to the work of Brauer et al. ${ }^{19}$ it is certain that the annealing in this work does not change the structure of virgin $\mathrm{SiO}_{2}$. As mentioned in Sec. III C, there is a high concentration of residual hydrogen in the $\mathrm{SiO}_{2} / \mathrm{Si}$ interface region although the sample is grown in a dry oxygen atmosphere. ${ }^{18}$ During post-growth annealing, hydrogen diffuses towards the surface of $\mathrm{SiO}_{2}$ so that it is nearly uniformly distributed in the $\mathrm{SiO}_{2}$ layer. ${ }^{18}$ Because hydrogen introduces low $S$ values in $\mathrm{SiO}_{2}$ by reducing the positronium formation probability, ${ }^{20,21}$ we see a clear decrease in $S$ after the virgin $\mathrm{SiO}_{2} / \mathrm{Si}$ sample is annealed at $1100{ }^{\circ} \mathrm{C}$ in nitrogen (Figs. 2-4).

When nc-Si is formed in $\mathrm{SiO}_{2}$ after the same annealing, the $S$ values are further reduced (Figs. 2-4). This is not due to the implantation-induced defects, which can be annealed out at $600{ }^{\circ} \mathrm{C} .{ }^{22}$ The Si nanocrystals themselves cannot account for this decrease, either. The diffusion length of positrons in defect-free $\mathrm{Si}$ is usually $215-250 \mathrm{~nm},{ }^{23}$ which is significantly larger than the sizes of $\mathrm{nc}-\mathrm{Si}$ in our sample. Moreover, it is known that many interfaces are normally introduced between the $\mathrm{SiO}_{2}$ matrix and nc-Si. The mismatch between them leaves open-volume spaces (voids) in the interface regions. They naturally have a better ability to trap positrons than both the normal $\mathrm{SiO}_{2}$ structure and $\mathrm{Si}$, inhibiting the quantum confinement of positrons in nc-Si no matter how different their positron affinities are. ${ }^{24}$ Hence, the probability of positron annihilation inside $\mathrm{nc}-\mathrm{Si}$ is 
negligible. ${ }^{25}$ Nitrogen also prefers to be trapped in these voids, leading to a larger amount of nitrogen incorporated during annealing in nitrogen and, therefore, smaller $S$ values are seen in PAS. The presence of nitrogen in a system of $\mathrm{Si}$ clusters embedded in $\mathrm{SiO}_{2}$ has been identified by x-ray photoelectron spectroscopy. ${ }^{26}$ There is also the possibility that some oxygen atoms could decorate the interfacial voids, similarly lowering the $S$ parameter. We should be also aware of the implantation-induced volume compaction in the structure of $\mathrm{SiO}_{2}$. This leads to the suppression of the formation of positronium, also contributing to the decrease of $S .{ }^{22}$ After $400{ }^{\circ} \mathrm{C}$ annealing in nitrogen, the trapping of nitrogen in the interface regions is saturated. This explains why $S$ values decrease and then hardly change until $700^{\circ} \mathrm{C}$ (Fig. 2).

As in nitrogen, $400^{\circ} \mathrm{C}$ annealing in oxygen introduces oxygen into the voids around nc-Si. This causes the decrease of $S$ (Fig. 3), which continues until $700^{\circ} \mathrm{C}$. In contrast, $400^{\circ} \mathrm{C}$ annealing in vacuum introduces no impurities. The substantial decrease in the value of $S$ suggests that the defects at the nc-Si/SiO $\mathrm{S}_{2}$ interface have already been decorated by nitrogen from the atmosphere or/and oxygen from the implantation-induced oxygen interstitials during the formation of nc-Si. It is supposed that the voids around nc-Si do not then trap hydrogen, but instead provide excellent diffusion channels. Consequently, whereas hydrogen in the normal $\mathrm{SiO}_{2}$ structure is not trapped in the $\mathrm{nc}-\mathrm{Si} / \mathrm{SiO}_{2}$ interface regions during $400{ }^{\circ} \mathrm{C}$ annealing in vacuum, it can diffuse to the $\mathrm{SiO}_{2}$ /substrate interface and is trapped by the interface defects there. The change of hydrogen concentration in the $\mathrm{SiO}_{2}$ layer is small so that $S$ values remain nearly the same as the as-formed sample (Fig. 4). The concentration of hydrogen in the $\mathrm{SiO}_{2}$ /substrate interface, however, is considerably increased because of its relatively small width (1-2 nm) ${ }^{8}$ compared with that of the $\mathrm{SiO}_{2}$ layer $(500 \mathrm{~nm})$. Positrons are sensitive to the presence of hydrogen in the interface region because of their propensity for localization in that region; this explains the decrease of $S$ around $7 \mathrm{keV}$ (Fig. 4). It is proposed that the absence of the decrease in $S$ at around $7 \mathrm{keV}$ after annealing at $400{ }^{\circ} \mathrm{C}$ in nitrogen or oxygen (Figs. 2 and 3) results from the suppression of hydrogen diffusion in the $\mathrm{SiO}_{2}$ layer by nitrogen and/or oxygen blocking its diffusion channels.

After washing the sample with acetone, the residual acetone may dissociate into $\mathrm{H}, \mathrm{O}-\mathrm{H}$, and $\mathrm{C}=\mathrm{O}$ during annealing at $400{ }^{\circ} \mathrm{C}$ in vacuum. It is supposed that $\mathrm{H}$ diffuses to the $\mathrm{SiO}_{2} /$ substrate interface, inducing a further decrease in $S$ around $8 \mathrm{keV}$ (Fig. 4). $\mathrm{O}-\mathrm{H}$ and $\mathrm{C}=\mathrm{O}$ could enter the normal structure of $\mathrm{SiO}_{2}$ or the voids around nc-Si, giving rise to the decrease in $S$ for the $\mathrm{SiO}_{2}$ layer. The dip at $8 \mathrm{keV}$ is closer to its "expected" value (i.e., corresponding to an interface depth of $500 \mathrm{~nm}$ ) because it is more pronounced and because diffusion effects have a weaker smearing effect on the raw data. At temperatures higher than $400{ }^{\circ} \mathrm{C}$ hydrogen becomes mobile and its presence at the interface is no longer significant enough to be seen in the raw positron data.

It is reasonable to assume that the trapping of oxygen in the voids increases with annealing temperature. After annealing at $700{ }^{\circ} \mathrm{C}$ in oxygen the PL peak is broadened [Fig. 1(c)]. This indicates inhomogeneous oxidation of nc-Si. ${ }^{27}$ Oxida- tion means that additional oxygen is incorporated in addition to that in the voids; both contribute to the decrease of $S$ after $700{ }^{\circ} \mathrm{C}$ annealing (Fig. 3).

The average size of nc-Si increases after the annealing at $700{ }^{\circ} \mathrm{C}$ in oxygen, as indicated by the redshift of the PL peak [Fig. 1(c)]. The agglomeration of nanocrystals and the volume increase induced by their oxidation both make smaller interface regions, and thus smaller void volume. This weakens the trapping of oxygen, but its effect on the positron measurements is not enough to counter the response to the two factors just discussed.

Agglomeration during annealing at $700{ }^{\circ} \mathrm{C}$ in nitrogen is negligible, as evidenced by the negligible shift of the PL peak [Fig. 1(a)]. The widening of the short-wavelength side of the PL peak, however, indicates that more small nanocrystals are produced. The average distance between nanocrystals in the as-formed sample is estimated to be $\sim 0.68 \mathrm{~nm}$. Assuming an activation energy of $1.9 \mathrm{eV}$ and a pre-exponential factor of $1.29 \times 10^{19} \mathrm{~cm}^{2} \mathrm{~s}^{-1}$ for the diffusion of $\mathrm{Si}$ in $\mathrm{SiO}_{2}$ in a nitrogen atmosphere, ${ }^{28}$ we find that a $\mathrm{Si}$ atom only travels $\sim 0.18 \mathrm{~nm}$ at $700^{\circ} \mathrm{C}$ in $30 \mathrm{~min}$. It is supposed that via the Ostwald ripening mechanism, ${ }^{29} \mathrm{Si}$ atoms dissociated from small nanocrystals do not move far enough to reach larger ones after $700^{\circ} \mathrm{C}$ annealing in nitrogen. This causes a decrease in the size of small nanocrystals without any growth of the neighboring ones. Apparently, the increase of the void volume induced by this process is not significant enough to enhance the trapping of nitrogen and to thus reduce $S$ values. The difference in the agglomeration between nitrogen and oxygen atmospheres implies that the diffusion of $\mathrm{Si}$ in $\mathrm{SiO}_{2}$ is slower in a nitrogen atmosphere.

We now turn to the PL results for annealing in vacuum. It is interesting that a small redshift of the PL peak appears even at $400^{\circ} \mathrm{C}$ after washing with acetone [Fig. 1(d)], in contrast to the annealing in nitrogen, oxygen, and vacuum. The unique element introduced by acetone is carbon compared with the others, which all involve the unintentionally incorporated hydrogen. Hence, we believe that carbon may enhance $\mathrm{Si}$ diffusion in $\mathrm{SiO}_{2}$, resulting in the agglomeration of nc-Si at low annealing temperatures. The redshift of the PL peak after $700^{\circ} \mathrm{C}$ annealing in vacuum is clearly larger than in nitrogen [Figs. 1(a) and 1(e)], again implying the slow $\mathrm{Si}$ diffusion in $\mathrm{SiO}_{2}$ in a nitrogen atmosphere. The underlying mechanism for these different diffusion phenomena needs further study.

Above $700{ }^{\circ} \mathrm{C}$ in nitrogen, $\mathrm{Si}$ atoms can move farther so that the agglomeration of nc-Si takes place. This is evidenced by the small redshift of the PL peak after the annealing at $900^{\circ} \mathrm{C}$ in nitrogen [Fig. 1(b)]. As in oxygen, the broadening of the PL peak may be due to a nitridation process of nc-Si at high temperature. Both the size increase and nitridation reduce the interface regions and thus the volume of voids. Assuming that the trapping rate of nitrogen in voids is nearly the same as at low temperatures, the resultant decrease in the amount of nitrogen gives rise to the recovery of $S$. The reduction of positron trapping in the interface regions is compensated by the increase in the intrinsic open volume of the $\mathrm{SiO}_{2}$ matrix. The latter is characterized by high $S$ values because of the probable formation of positronium. ${ }^{30}$ After 
$900^{\circ} \mathrm{C}$ annealing in nitrogen, the fraction of positrons annihilated in the $\mathrm{SiO}_{2}$ matrix becomes high enough to increase measured $S$ values to above those for the as-formed sample (Fig. 2).

On annealing at high temperature in oxygen, the enhanced $\mathrm{Si}$ diffusion in $\mathrm{SiO}_{2}$ results in more effective agglomeration of nc-Si. This is illustrated by the considerable redshift of PL peak after $900{ }^{\circ} \mathrm{C}$ annealing in oxygen [Fig. 1(c)]. The more significant size increase, together with the oxidation process, introduces a larger shrinkage of the interface regions and the volume of associated voids than on annealing in nitrogen. The resultant decrease of positron trapping in the interface regions should have led to a larger recovery of $S$; however, $S$ values just recover to the level for the as-formed sample after $900{ }^{\circ} \mathrm{C}$ annealing in oxygen (Fig. 3), clearly lower than those for the sample annealed at the same temperature in nitrogen.

During oxidation the oxidized Si can introduce a volume increase by up to $100 \%$, which is $\sim 4$ times larger than that during nitridation. We believe that the volume increase of nc-Si (including their oxide shells) during the oxidation at $900{ }^{\circ} \mathrm{C}$ is so large that the intrinsic open volume of the $\mathrm{SiO}_{2}$ matrix shrinks to relax the stress induced by it. This shrinkage suppresses the formation of positronium in spite of the increase of the fraction of positrons annihilated in $\mathrm{SiO}_{2}$ as happens in the annealing at $900{ }^{\circ} \mathrm{C}$ in nitrogen, and the increase in $S$ is weakened.

\section{SUMMARY}

We find that nitrogen and oxygen are trapped in the voids around nc-Si at low annealing temperatures. It appears that the defects at the nc-Si/ $\mathrm{SiO}_{2}$ interface have already been completely passivated by nitrogen and/or oxygen in the asformed nc-Si sample. High-temperature annealing during the formation of nc-Si causes hydrogen to enter the $\mathrm{SiO}_{2}$ structure, which originally resides in the $\mathrm{SiO}_{2}$ /substrate region. Hydrogen diffuses back to the $\mathrm{SiO}_{2} /$ substrate region in vacuum at $400{ }^{\circ} \mathrm{C}$ because no other impurities block its diffusion channels. At temperatures above $700{ }^{\circ} \mathrm{C}$, both nitrogen and oxygen react with nc-Si, resulting in a volume increase. This introduces stress in the $\mathrm{SiO}_{2}$ matrix, which is relaxed by the shrinkage of its intrinsic open volume. Moreover, it is proposed that nitrogen suppresses $\mathrm{Si}$ diffusion in $\mathrm{SiO}_{2}$, so that the agglomeration of nc-Si is slower during annealing in nitrogen than in oxygen or vacuum.

\section{ACKNOWLEDGMENTS}

This work is supported by EPSRC Grants GR/M51895 and GR/M54001. We are grateful to S. Zeng, Dr. D. Wolver- son, and Prof. A. T. Collins for the help in the PL measurements. We should like to thank Prof. W. N. Wang for providing us with the annealing facility.

${ }^{1}$ L. Pavesi, L. D. Negro, C. Mazzoleni, G. Franzó, and F. Priolo, Nature (London) 408, 440 (2000).

${ }^{2}$ M. H. Nayfeh et al., Appl. Phys. Lett. 80, 121 (2002).

${ }^{3}$ J. P. Proot, C. Delerue, and G. Allan, Appl. Phys. Lett. 61, 1948 (1992).

${ }^{4}$ M. V. Wolkin, J. Jorne, P. M. Fauchct, G. Allan, and C. Delerue, Phys. Rev. Lett. 82, 197 (1999).

${ }^{5}$ B. Nielsen, K. G. Lynn, Y.-C. Chen, and D. O. Welch, Appl. Phys. Lett. 51, 1022 (1987).

${ }^{6}$ P. Asoka-Kumar, K. G. Lynn, and D. O. Welch, J. Appl. Phys. 76, 4935 (1994).

${ }^{7}$ R. Krause-Rchberg and H. S. Leipner, Positron Annihilation in Semiconductors: Defect Studies (Springer, Berlin, 1999).

${ }^{8}$ H. L. Au, P. Asoka-Kumar, B. Nielsen, and K. G. Lynn, J. Appl. Phys. 73, 2972 (1993).

${ }^{9}$ R. Khatri, P. Asoka-Kumar, B. Nielsen, L. O. Roellig, and K. G. Lynn, Appl. Phys. Lett. 65, 330 (1994).

${ }^{10}$ P. Asoka-Kumar, K. G. Lynn, and D. O. Welch, J. Appl. Phys. 76, 4935 (1994).

${ }^{11}$ M. P. Petkov, T. Marek, P. Asoka-Kumar, K. G. Lynn, R. S. Crandall, and A. H. Mahan, Appl. Phys. Lett. 73, 99 (1998).

${ }^{12}$ P. G. Coleman, N. B. Chilton, and J. A. Baker, J. Phys.: Condens. Matter 2, 9355 (1990).

${ }^{13}$ M. Fujinami, Phys. Rev. B 53, 13047 (1996).

${ }^{14}$ A. Uedono, T. Kitano, K. Hamada, T. Moriya, T. Kawano, S. Tanigawa, R. Suzuki, T. Ohdaira, and T. Mikado, Jpn. J. Appl. Phys., Part 1 136, 2571 (1997).

${ }^{15}$ X. D. Pi, C. P. Burrows, and P. G. Coleman, Phys. Rev. Lett. 90, 155901 (2003).

${ }^{16}$ N. B. Chilton and P. G. Coleman, Meas. Sci. Technol. 6, 53 (1995).

${ }^{17}$ J. C. D. Vos, Physica (Amsterdam) 20, 690 (1954).

${ }^{18}$ A. G. Revesz, J. Electrochem. Soc. 126, 122 (1979).

${ }^{19}$ G. Brauer and G. Boden, Diffus. Defect Data 53-54, 173 (1987).

${ }^{20}$ M. Fujinami, N. B. Chilton, K. Ishii, and Y. Ohki, J. Appl. Phys. 74, 5406 (1993).

${ }^{21}$ A. Uedono, L. Wei, S. Tanigawa, R. Suzuki, H. Ohgaki, T. Mikado, and K. Fujino, J. Appl. Phys. 75, 216 (1994).

${ }^{22}$ A. P. Knights, P. J. Simpson, L. B. Allard, J. L. Brebner, and J. Albert, J. Appl. Phys. 79, 9022 (1996).

${ }^{23}$ P. J. Schultz, E. Tandberg, K. G. Lynn, B. Nielsen, T. E. Jackman, M. W. Denhoff, and G. C. Aers, Phys. Rev. Lett. 61, 187 (1988).

${ }^{24}$ M. A. van Huis, A. van Veen, H. Schut, C. V. Falub, S. W. H. Eijt, P. E. Mijnarends, and J. Kuriplach, Phys. Rev. B 65, 085416 (2002).

${ }^{25}$ G. Ghislotti, B. Nielsen, P. Asoka-Kumar, K. G. Lynn, L. F. D. Mauro, F. Corni, and R. Tonini, Appl. Phys. Lett. 70, 496 (1997).

${ }^{26}$ Q. Zhang, S. C. Bayliss, and D. A. Hutt, Appl. Phys. Lett. 66, 1977 (1995).

${ }^{27}$ G. Ledoux, O. Guillois, D. Porterat, C. Reynaud, F. Huisken, B. Kohn, and V. Paillard, Phys. Rev. B 62, 15942 (2000).

${ }^{28}$ L. A. Nesbit, Appl. Phys. Lett. 46, 38 (1985).

${ }^{29}$ W. Ostwald, Z. Phys. Chem. (Munich) 34, 495 (1900).

${ }^{30}$ M. Hasegawa, M. Saneyasu, M. Tabata, Z. Tang, Y. Nagai, T. Chiba, and Y. Ito, Nucl. Instrum. Methods Phys. Res. B 166-167, 431 (2000). 